\title{
Whether satisfaction with and liking for the supervisor moderate the relationship between fair treatment and employee internet behaviour
}

\author{
Pablo Zoghbi-Manrique-de-Lara* and \\ Antonia M. Gil-Padilla \\ Institute of Tourism and Sustainable Development (TIDES), \\ University of Las Palmas de Gran Canaria, \\ 4c/ Saulo Torón, Campus Tafira Baja, \\ 350017 Las Palmas de Gran Canaria, \\ The Canary Islands, Spain \\ E-mail: pzoghbi@dede.ulpgc.es \\ E-mail: agil@dede.ulpgc.es \\ *Corresponding author
}

\begin{abstract}
The current study aims to elaborate on the link between perceptions of interactional justice (IJ) - a specific type of organisational justice that reflects how an employee is treated by an authority figure - and internet behaviour. We first discuss what is unique about internet behaviour by focusing on two cyber activity categories, cyberloafing and cybercivism, performed by university instructors. Drawing on prior research suggesting that judgments about the supervisor may create schemas that can determine subsequent responses, we predict stronger influences of IJ on internet behaviour in those employees who display higher rather than lower liking for their supervisor and satisfaction with supervisor performance. Furthermore, just as prior research found for conventional deviance and citizenship, the paper hypothesises that cyberloafing and cybercivism are negatively inter-correlated. The results do not support main effects of IJ on these internet behaviours, while employees with comparatively high satisfaction with their supervisor's performance responded to IJ with less cyberloafing and more cybercivism. Contrary to expectations, the predicted inter-correlation was not supported and employees with relatively high liking for the supervisor responded to IJ by displaying more cyberloafing and the same cybercivism. Finally, the threeway interaction terms decreased cyberloafing but failed to increase cybercivism. Implications for research and practice are discussed.
\end{abstract}

Keywords: internet behaviour; cybercivism; cyberloafing; interactional justice; subordinate appraisals of supervisor; liking for supervisor; fair treatment.

Reference to this paper should be made as follows: Zoghbi-Manrique-de-Lara, P. and A.M. Gil-Padilla (2012) 'Whether satisfaction with and liking for the supervisor moderate the relationship between fair treatment and employee internet behaviour', Int. J. Internet and Enterprise Management, Vol. 8, No. 1, pp.66-85.

Biographical notes: Pablo Zoghbi-Manrique-de-Lara received his $\mathrm{PhD}$ in Business Administration at Las Palmas de Gran Canaria University, Spain. He is an Associate Professor in HR Management and Organisational Behaviour of the Institute of Tourism and Sustainable Development (TIDES). He spent six years in industry and finance, training and HR management positions (mainly 
with El Corte Ingles and Ionics) prior to his return to academia. His primary research interests include issues surrounding the causes and consequences of deviant and citizenship behaviours in organisations.

Antonia M. Gil-Padilla received his $\mathrm{PhD}$ in Business Administration at Las Palmas de Gran Canaria University, Spain. He is an Associate Professor in Information System Management of the Institute of Tourism and Sustainable Development (TIDES).

\section{Introduction}

In recent years, due to the omnipresence of information and communication technologies (ICTs) at work, organisational behaviour scholars have paid a considerable amount of attention to employees' cyber activity. Two examples of this cyber activity at work are cyberloafing (e.g., Lim, 2002; Lim and Teo, 2005), or the employees' misuse of the company's internet resources, and cybercivism (Zoghbi-Manrique-de-Lara, 2007), or the citizenship usage of these resources. Generally conceptualised as deviant workplace behaviour, the term cyberloafing is defined by Lim (2002) as employees' voluntary use of their companies' internet access for non-work-related purposes during working hours. Cyberloafing has become an important issue for organisations. Malachowski (2005) refers to this inappropriate use of the internet as the most common way for employees to waste time at work. Anecdotal evidence from Fox (2007) also suggests that some employees spend as many as $5-6 \mathrm{~h}$ a day surfing the internet at work. The term cybercivism, on the other hand, has been used to describe organisational citizenship behaviour (OCB) performed over the internet (Zoghbi-Manrique-de-Lara, 2007). These exemplary behaviours that employees display discretionally and that promote their organisation's effectiveness (Organ, 1988) would include helping users by responding to misdirected e-mails and taking care of the organisation's network by avoiding virus risks and other threats. Described in these terms, cybercivism may have beneficial consequences for organisations, such as preventing information security incidents originating from within the organisation and favouring the e-service provided via the internet.

Organisational research literatures offer two main strategies for managing these 'internet behaviours' at work (so referenced hereinafter):

- extrinsically-oriented coercive strategies (from Lat. coerč̌o, -ōnis: to contain, restraint, repression), where employees' behaviour is enforced by external contingencies in their environment (e.g., Liao et al., 2010; Zoghbi-Manrique-de-Lara et al., 2006; Henle and Blanchard, 2008)

- intrinsically-oriented self-regulatory strategies, which are linked to intrinsic motivational models of human behaviour.

The presence of the latter approach within the literature on employee cyber activity is significant. Lim (2002) and Lim and Teo (2005) found, for example, that designing a workplace perceived by employees as fair can be an effective self-regulatory strategy to manage cyberloafing. Thus, they found employees to be less prone to engaging in cyberloafing to the extent to which managers elicit perceptions of organisational justice. 
Prior research on cybercivism, on the other hand, indicates that it follows similar patterns (Zoghbi-Manrique-de-Lara and Melián-González, 2009).

Intrinsically-oriented self-regulatory strategies for managing internet behaviour at work have incorporated a limited number of the advances made in the field of organisational justice (e.g., Henle et al., 2009; Lee et al., 2004). While coercive practices appear to be solidly based on the existing research in successfully tackling cyber activity at work (e.g., Henle and Blanchard, 2008; Liao et al., 2010; Zoghbi-Manrique-de-Lara et al., 2006), organisational academics have seldom discussed intrinsically-oriented self-regulatory practices, beyond emphasising the benefits of general perceptions of fair procedures, equitable distributions of rewards and respectful treatment of the supervisor (e.g., Beugré, 2006; Henle et al., 2009). Most of the scant attention paid to fairness in this respect has only focused on mixed strategies which try, by incorporating organisational justice, to lead cyber loafers and civic employees to perceive control mechanisms as fair and legitimate (Hovorka-Mead et al., 2002; Stanton, 2000) and punishment as just (e.g., Ball et al., 1994). Unfortunately, this has not occurred in the case of intrinsically-oriented self-regulatory strategies focusing on the role that a fair authority figure can play in supervising internet behaviour in the workplace and how employee feelings affect the supervising role of that fair authority. Furthermore, some studies suggest (Maruping and Agarwal, 2004) that not all of the conventional literature is necessarily relevant or directly applicable to cyber activity. There are contextual specificities (such as perceived anonymity, fewer social sanctions, less recognition and social distance, among others) that may cause internet behaviours to have unique features compared to conventional citizenship and deviance.

To further examine an intrinsically-oriented strategy based on internet behaviour and fair supervision, we should first consider focusing on interactional justice (IJ), since this specific type of organisational justice particularly reflects how employees are treated by their supervisors (Bies and Moag, 1986). Although a general prediction in the organisational and social psychology literature is that employee behaviour is often triggered by a provocative event or series of events (Weiss and Cropanzano, 1996), we agree with Aquino et al. (2004) when they state that "... not everyone who is treated unjustly by his or her supervisor at work responds by engaging in deviance" (p.1002), and with Folger and Skarlicki (1998) when they question whether IJ (hereinafter IJ) is able to predict retaliation in the workplace (unless IJ is also perceived as a lack of interpersonal sensitivity). Thus, by itself, the IJ-internet behaviour link appears to be overly reductionist in modelling employees' reactions to IJ. In predicting associations between IJ and internet behaviour, we expect them to be weak but likely to be strengthened by uncovering conditions under which IJ ultimately triggers internet behaviour. In so doing, this paper aims to contribute to helping fair authority figures to become more effective in managing internet behaviour, thus leading to the success of intrinsically-oriented supervisory strategies.

Implicit leadership theories (e.g., Bass, 1990; Lord et al., 2001) suggest that judgments about the supervisor may create mental models or frameworks that can determine previous conditions under which employees interpret supervisory events. This paper is based on these theories and proposes liking for the supervisor and subordinates' appraisals of managers as parts of these 'frameworks of emotions and cognitions' about the supervisor under which employees might interpret IJ events. We suggest these two constructs specifically because, as Judge et al. (2006) suggested, affective and cognitive mechanisms can explain how and when an employee reacts to interpersonal indignities. 
Liking for the supervisor appears to have a clear emotional component and prior literature on emotional feelings at work has reported emotions as powerful triggers for behaviour among employees facing injustice (see also, e.g., Skarlicki and Latham, 1997; Organ et al., 2006). In addition, as Bernardin (1986) suggested, subordinates' appraisals of managers are important cognitions in determining employee behaviour. Prior research on internet behaviour has reported cognitive mechanisms (e.g., neutralisation) as likely to be present in employees' minds as an explanation for why they respond to IJ in the form of internet behaviour (Lim, 2002; Lee and Allen, 2002).

Finally, since some prior research has supported conventional deviance and citizenship as two distinct but negatively correlated constructs (e.g., Kelloway et al., 1999), we expect the two internet behaviours to be significantly negatively inter-correlated. In sum, the structure of the present paper is as follows. First, it will discuss the theoretical distinctiveness of the two internet behaviours under study, based on conventional deviance and citizenship, to finally test whether they are negatively correlated. Meanwhile, we plan to examine whether feelings of liking for the supervisor and employees' satisfaction with the supervisor's performance (even jointly) positively moderate (either intensifying or 'triggering') the influence of IJ on internet behaviour. As far as we know, there has been no previous empirical work on these predictions.

\section{Theoretical background and hypotheses}

\subsection{The uniqueness of internet behaviour}

To date, even though the two studied cyber activities have been clearly described and defined by the literature, a scholarly discussion about what is unique about employees' internet behaviour, compared to conventional deviance and citizenship, is still pending. Zoghbi-Manrique-de-Lara (2007) defined cybercivism as any "IT extra-role behaviour that includes a voluntary act by employees - while using internet access during office hours - intended to care for the company's information system and help its users" (p.44). At a glance, this definition appears to suggest that cybercivism is just care and help while online, but it does not clarify that these behaviours have to be delivered online. Furthermore, as in the case of conventional citizenship, cybercivism is an extra-role behaviour [to use the Van Dyne et al. (1995) terminology] and shares the same targets found in Williams and Anderson (1991) for conventional citizenship - i.e., individuals and the organisation as a whole. On the other hand, by defining cyberloafing as “... non-job related web sites for personal purposes", Lim (2002, p.677) does not appear to conceptualise cyberloafing as a distinct form of conventional deviance either. Instead, cyberloafing seems to be considered workplace production deviance that merely targets the internet resources of the organisation (e.g., Lim, 2002; Lim and Teo, 2005). Hence, what is really unique about internet behaviour?

Since internet behaviour is a human activity, it stems from real rather than virtual behaviour. Thus, the actions of connecting to the internet, reading and writing responses to misdirected e-mails, or wasting time at work, for instance, are verifiable acts of internet behaviour from a strictly real perception. Unlike conventional deviance, these behaviours are carried out by employees while they are connected online, raising the probability that they constitute virtual activity. Indeed, employees' internet behaviour involves 'logging out' other users and ignoring their e-mails, delaying online work, 
increasing their presence in virtual groups, accepting a proposed plan of action online, or just being 'available' to user needs. Even though these behaviours can be the object of a real perception, it is clear that they cannot be considered as merely misusing (or citizenship using) the internet resources of the organisation. Indeed, as stated in Organ (1997) regarding conventional citizenship, cybercivism appears to support the technical core of the organisation, but over the internet. Thus, by capturing 'facilitative' behaviours, cybercivism may be helpful in facing specific difficulties of virtual contexts that are not present in face-to-face settings - e.g., the distance that virtual contexts create. Concerning cyberloafing, on the other hand, prior research also provides evidence suggesting that cyberloafing not only influences employees' work and emotions as a human-computer interaction phenomenon (Lim and Chen, 2012), but it can also harm targets via the internet (Zoghbi-Manrique-de-Lara, 2011). Furthermore, internet behaviour can be harmful or beneficial for reasons (e.g., leading other individuals or client-users to $\log$ out) that are very different from those existing in face-to-face contexts (e.g., upsetting them while waiting at their desks).

Table 1 Comparison between internet behaviour and conventional OCB and deviance

\begin{tabular}{|c|c|c|}
\hline & Internet behaviour & Conventional $O C B$ and deviance \\
\hline $\begin{array}{l}\text { Medium in which } \\
\text { they mostly take } \\
\text { place }\end{array}$ & Face-to-face and virtual & Face-to-face \\
\hline $\begin{array}{l}\text { Origin of the } \\
\text { behaviour }\end{array}$ & $\begin{array}{l}\text { It stems from real behaviour, but can } \\
\text { become online behaviour }\end{array}$ & It is always real behaviour \\
\hline Span & $\begin{array}{l}\text { In the case of cyberloafing, it is limited } \\
\text { to production deviance }\end{array}$ & Multidimensional \\
\hline Target & $\begin{array}{l}\text { In the case of cyberloafing the target } \\
\text { is the organisation only, although in } \\
\text { subsequent interactions harm may occur }\end{array}$ & Organisation and individuals \\
\hline \multirow[t]{3}{*}{$\begin{array}{l}\text { Harmful or } \\
\text { beneficial impact }\end{array}$} & $\begin{array}{l}\text { In the case of cyberloafing, it may be } \\
\text { counter-productive, innocuous and even } \\
\text { beneficial (e.g., to cope stress) (Bock } \\
\text { and Ho, 2009; Lim and Chen, 2012; } \\
\text { Zoghbi-Manrique-de-Lara, 2011). }\end{array}$ & $\begin{array}{l}\text { Conventional deviance is, per se, } \\
\text { counter-productive and usually } \\
\text { interferes with the technical } \\
\text { core itself (e.g., employee theft). } \\
\text { Conventional OCB sup-ports }\end{array}$ \\
\hline & $\begin{array}{l}\text { In the case of cybercivism, it is, per se, } \\
\text { productive, by supporting the technical } \\
\text { core across the internet as a contextual } \\
\text { activity (e.g., increasing presence in } \\
\text { virtual groups) (Borman and } \\
\text { Motowidlo, 1997). }\end{array}$ & \multirow[t]{2}{*}{$\begin{array}{l}\text { Conventional OCB sup-ports } \\
\text { the technical core by merely } \\
\text { considering internet as a technical } \\
\text { resource (e.g., increasing its } \\
\text { effective functioning) } \\
\text { (Yen et al., 2008) }\end{array}$} \\
\hline & $\begin{array}{l}\text { In both cases, they impact performance } \\
\text { as con-textual activities (Borman and } \\
\text { Motowidlo, 1997) }\end{array}$ & \\
\hline
\end{tabular}


Table 1 Comparison between internet behaviour and conventional OCB and deviance (continued)

\begin{tabular}{lll}
\hline & \multicolumn{1}{c}{ Internet behaviour } & Conventional OCB and deviance \\
\hline Virtual features & $\begin{array}{l}\text { Mediating technology constrains the } \\
\text { breadth of the behaviours (IJsselsteijn } \\
\text { et al., 2003; Lea and Spears, 1992; }\end{array}$ & $\begin{array}{l}\text { Anecdotal (e.g., to use e-mail for } \\
\text { harassment purposes at work) }\end{array}$ \\
& Zoghbi-Manrique-de-Lara, 2011). \\
& Virtual communication is indeed a \\
& breeding ground for misinterpretations \\
& and cybercivism can include frequent \\
& over-emphasised expressions (Ferguson \\
& and Ferguson, 1988; Walther, 1992). \\
& Visibility is limited by the need of & \\
& others to access the virtual medium. & \\
& This perceived anonymity can inhibit \\
personality and place contextual & \\
constraints on behaviour. & \\
& Possibility that it does not come & \\
from the actions of a real person & \\
Employee & Perceived anonymity and the greater & Motivation is not limited by virtual \\
motivation & social distance in virtual contexts can \\
& cause internet behaviour to be driven \\
& by social sanctions and recognition to \\
& a lesser extent (IJsselsteijn et al., 2003; \\
& Lea and Spears, 1992).
\end{tabular}

If internet behaviour is able to operate over the internet, we are talking about behaviours that 'exist' fundamentally as a consequence of the mechanisms that support the internet context; thus, the ontology of these behaviours should be linked to this fact. Otherwise, can we talk about the behaviours without simultaneously considering the medium through which they are delivered? It is clear that the behaviour is an immutable fact: when it has already happened - whatever it is - it cannot be changed. However, depending on the particular specificities of the context, the targets might experience it differently. As the 'context' in which these cyber activities are conducted becomes a very different sort of operating environment and the mediating technology in some way constrains the breadth of the behaviour (Lea and Spears, 1992), the fundamental nature of the interactions in internet and face-to-face environments is different. Employees cope with this fact by shaping a behaviour that is more capable of addressing these contextual contingencies efficiently (e.g., using online help resources such as gestural icons or over-emphasised expressions, among others). Unlike when engaging in conventional citizenship and deviance, employees can sense social distance from other users to a greater extent, as well as greater anonymity and less recognition and likelihood of being socially sanctioned (IJsselsteijn et al., 2003). Therefore, employees cannot self-report their internet behaviour as being equal to other acts of conventional citizenship and deviance, since they lose control of how their internet behaviours are experienced (Ferguson and Ferguson, 1988). Although employees are just behaving while online, they are likely to exhibit internet behaviours articulated in specific ways and as distinct behaviours. Table 1 summarises the key points of the above discussion. 


\subsection{The moderating role of liking for the supervisor and satisfaction with supervisor performance}

IJ comprises both interpersonal justice, or the degree to which those in authority treat individuals with dignity, respect and politeness and informational justice, or the extent to which communication between supervisors and subordinates is clear, candid and sufficient (Greenberg, 1993). As Judge et al. (2006) found, the influences of IJ on employee behaviour actually involve cognitions (e.g., disparity provoked by evaluations about supervisor misinformation) as well as emotions (e.g., outrage/trust provoked by interpersonal mis/treatment). As internet behaviours are either affect-driven or judgment-driven, it is expected that employee perceptions of IJ will motivate cybercivism and discourage cyberloafing.

H1a Employees' perceptions of IJ and cyberloafing are negatively associated.

H1b Employees' perceptions of IJ and cybercivism are positively associated.

\subsection{The moderating role of liking for the supervisor and satisfaction with supervisor performance}

As mentioned above, implicit leadership theories (Bass, 1990; Lord et al., 2001) suggest that employee judgments about the supervisor may create 'schemas' that can determine conditions under which employees interpret the supervisor's performance. Since employees' liking and satisfaction with the supervisor's performance are affective and evaluative feelings, respectively, they are likely to affect employee behaviour by interacting on the above-mentioned emotional and cognitional aspects of IJ. Thus, by exacerbating or diluting the emotional and cognitional aspects of IJ in employees' minds, satisfaction with and liking for the supervisor could trigger internet behaviour.

As an example, employees who rate highly 'the performance that their boss has always shown' would act under the influence of this previous positive judgment, be more likely to overrate the supervisor's informational justice (i.e., in informing clearly and sufficiently) and excuse faults in this regard. Under these preconceived 'cognitive frameworks', satisfaction with supervisor performance is likely to play a decisive role in determining whether or not the employee engages in internet behaviour in the end.

$\mathrm{H} 2 \mathrm{a}$ Satisfaction with their supervisors' performance strengthens the negative relationship between employees' perceptions of IJ and cyberloafing.

$\mathrm{H} 2 \mathrm{~b}$ Satisfaction with their supervisors' performance strengthens the positive relationship between employees' perceptions of IJ and cybercivism.

However, as discussed above, since internet behaviour can be affect-driven, it may also be the result of an employee's emotional state induced by a lack of IJ. Thus, with implicit leadership theories in mind, Weiss and Cropanzano (1996, p.37) state that "affective traits appear to act as latent predispositions", and individuals involved in negative affectivity are 'predisposed to react more strongly to negative events'. With these ideas as a guide, we would suggest that an employee who likes his or her supervisor may reduce the importance of episodes of anger originated by an IJ event. In this respect, the employee might recognise that "again and again, although my boss makes me angry (because of interpersonal unfairness), once I can appreciate his or her friendliness, my 
anger disappears". Under this liking for the supervisor, emotional states generated by IJ may be neutralised (or exacerbated); hence, liking for the supervisor may ultimately arbitrate whether or not employees respond to IJ with internet behaviour.

H3a Employees' liking for their supervisors strengthens the negative relationship between employees' perceptions of IJ and cyberloafing.

H3b Employees' liking for their supervisors strengthens the positive relationship between employees' perceptions of IJ and cybercivism.

\subsection{The joint moderating role of liking for the supervisor and satisfaction with supervisor performance}

A reasonable principle in the social psychology literature is that individuals' emotional and cognitive processes are not two 'watertight compartments', but they actually perform interdependently. Therefore, in trying to control their own emotional states, individuals frequently cope with un/pleasant emotions by using rationalisations and judgments, thus expanding their perspectives. However, individuals' judgments are also at risk of being biased if they are contaminated by positive or negative emotions. These transverse influences suggest a three-way interaction in which liking for the supervisor and satisfaction with the supervisor's performance would significantly interact on internet behaviour together with IJ. As an example, an employee high in both satisfaction with supervisor performance and liking would be likely to make an effort to excuse the unfair treatment (IJ) of his or her supervisor, "given that he/she always shows efficient performance, and I like him or her..." Thus, the combination of liking and satisfaction with the supervisor's performance would generate a more powerful condition that is able to further reinforce the relationship between IJ and internet behaviour.

$\mathrm{H} 4 \mathrm{a}$ There will be a three-way positive interaction effect of employees' perceptions of IJ, satisfaction with their supervisors' performance and liking for their supervisors on cyberloafing.

H4b There will be a three-way positive interaction effect of employees' perceptions of IJ, satisfaction with their supervisors' performance and liking for their supervisors on cybercivism.

\subsection{Inter-correlation between the two studied categories of internet behaviour}

Past research has pointed out the symmetry between conventional citizenship and deviance and the fact that the two behaviours are separate but correlated constructs (Kelloway et al., 1999). In addition, Spector and Fox (2002) developed an integrative model of 'voluntary work behaviour' that supports the notion that citizenship and counterproductive behaviours in traditional contexts follow opposite paths. Without doubt, internet behaviours unrelated to normal job duties show a certain parallelism to these conventional citizenship and deviance patterns, suggesting that they may be intercorrelated as well (see Figure 1).

H5 The two studied categories of internet behaviour (i.e., cyberloafing and cybercivism) are negatively inter-correlated. 
Figure 1 Hypothesised model of liking for the supervisor and satisfaction with the supervisor's performance as moderators of the link between IJ and internet behaviour

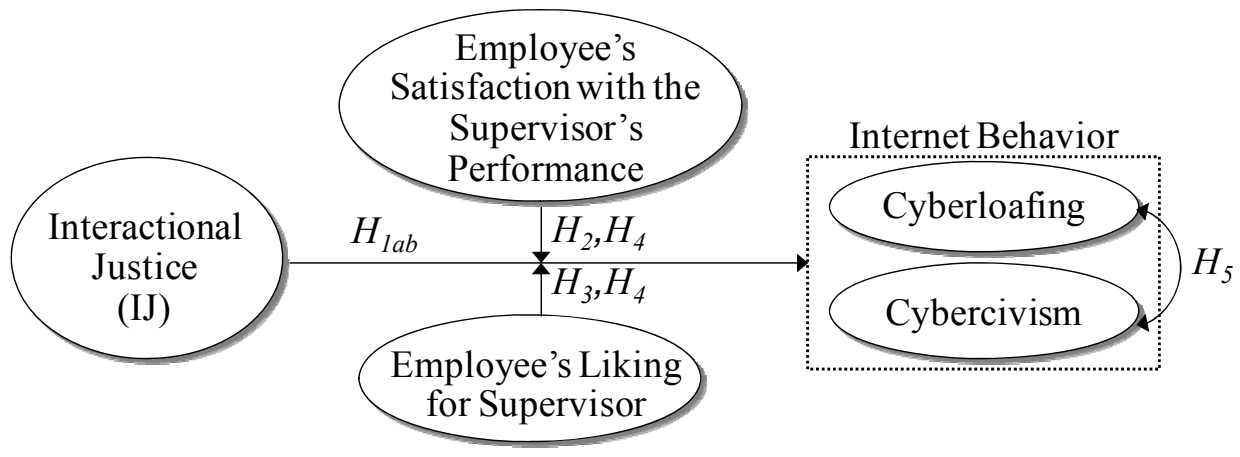

\section{Method}

\subsection{Procedure and sample characteristics}

Data were collected from $270(17.46 \%)$ of the 1547 teachers at a Spanish state university by means of a questionnaire that was posted on the intranet and could be accessed via a link in the e-mails asking for collaboration. The sample comprised $64.6 \%$ males and $35.4 \%$ females and while $40 \%$ were 40 years old or younger, only $4.2 \%$ were older than 60 . Most $(68 \%)$ of the sample held tenured positions, while the remainder did not. We found no contextual conditions leading us to presume varying willingness to respond. In recent years, the university's internet policy to combat inappropriate use has been increasingly enforced. Unfortunately, at this time, no parallel policies to promote citizenship web usage have been developed. The research project received prior official approval. In addition, IP addresses were unidentifiable and the potential respondents were so informed in order to avoid reticence and interference in their responses. Eventually, there were 270 valid responses, after five were rejected due to incorrect completion and seven due to incoherent information.

\subsection{Measures}

All the items were scored on a seven-point scale ranging from (1) strongly disagree to (7) strongly agree, and from (1) never to (7) constantly, in the case of internet behaviour. The items are presented in the Appendix. The Cronbach's alpha values are shown on the main diagonal of the correlations table (Table 2).

- $\quad I J:$ We used six items from the scale developed by Moorman (1991) regarding subordinates' perceptions of how fairly their supervisors treat them.

- Employee liking for the supervisor: We used the three-item scale developed by Wayne and Ferris (1990) and Wayne and Liden (1995) to measure supervisor liking for the subordinate, with higher scores representing a more positive affect. We changed the referent from 'supervisor' to 'employee'. 
- Satisfaction with the supervisor's performance: Satisfaction with supervisor performance was assessed with a four-item measure developed by the author after a review of the literature on leadership (Bass, 1990; Lord et al., 2001). Two reverse-scored items were automatically recoded.

- Cyberloafing: We used a five-item scale adapted from the one proposed by Lim (2002) to assess cyberloafing, which originally included eight items referring to browsing activities and three referring to e-mail activities. We selected four of the former and one of the e-mail activities, which combined Lim's 'send' and 'read' e-mail. Lim's third item, 'check' e-mail, was omitted, since we believe it overlaps with 'read' e-mail. One-dimensionality of the scale is expected. All the chosen items refer to presumed surfing misuse according to the university policy and normative on internet usage.

- Cybercivism: We used Zoghbi-Manrique-de-Lara's (2007) three-item scale to assess cybercivism. The coefficient alpha for the loaded three-item scale was 0.685 , close to the recommended alpha of 0.70 (Nunnally, 1978).

- Control variables: Drawing on the literature, gender $(0=$ male, $1=$ female $)$ and age $(1=$ from 23 to $30 ; 2=31-40 ; 3=41-50 ; 4=51-60 ; 5=61-70 ; 6=71-75)$ could co-vary with our in/dependent variables (Aquino et al., 2004). As the sample comprises university teachers, the doctoral degree was also include ( $1=$ yes, $2=$ no).

We used structural equation modelling (SEM) to ensure that the above variables were five separate constructs. To that aim, we inspected the fit of the five-factor structure for all the data in the study, and then examined how it differs from the fit for the one-factor structure.

Table 2 Means, standard deviations, correlations and reliabilities

\begin{tabular}{lcccccccccc}
\hline Variables & $M$ & $S D$ & 1 & 2 & 3 & 4 & 5 & 6 & 7 & 8 \\
\hline 1 Gender & 1.36 & 0.48 & - & & & & & & & \\
2 Age & 2.78 & 0.88 & -0.08 & - & & & & & & \\
3 Doctorate & 1.32 & 0.47 & -0.05 & -0.06 & - & & & & & \\
4 IJ & 4.34 & 1.74 & -0.12 & -0.04 & 0.11 & $(0.949)$ & & & & \\
5 Liking & 4.12 & 1.86 & -0.11 & -0.27 & 0.08 & $0.79^{* *}$ & $(0.933)$ & & & \\
6 Satisfaction & 4.01 & 1.53 & $-0.14^{*}$ & -0.42 & 0.07 & $0.61^{* *}$ & $0.52^{* *}$ & $(0.783)$ & & \\
7 Cyberloafing & 2.87 & 1.57 & $-0.25^{* *}$ & $-0.14^{*}$ & -0.06 & 0.12 & 0.05 & 0.09 & $(0.862)$ & \\
8 Cybercivism & 5.10 & 1.38 & $0.13^{*}$ & 0.01 & -0.04 & 0.03 & 0.09 & 0.02 & 0.00 & $(0.685)$ \\
\hline
\end{tabular}

Notes: The numbers in parentheses on the diagonal are coefficient alphas.

Levels of significance: ${ }^{*} p<0.05 ; * *<0.001$.

\section{Results}

The CFA results showed that the five-factor solution was acceptable $\left(\chi^{2}=330.314\right.$, $p<0.001 ; \mathrm{GFI}=0.900, \mathrm{CFI}=0.961, \mathrm{NFI}=0.919, \mathrm{RMSEA}=0.056)$. An inspection of the CFA results, shown in full detail in the Appendix, reveals that the indices are 0.90 or above and the RMSEA is close to 0.05 , providing support for the distinctiveness of the 
five constructs used in this study. In addition, the five-factor model was significantly better, $\Delta \chi^{2}(10)=969,892, p<0.05$, than the one-factor model $\left(\chi^{2}=1,300.206\right.$, $p<0.001, \mathrm{GFI}=0.633, \mathrm{CFI}=0.712 \mathrm{NFI}=0.680, \mathrm{RMSEA}=0.148)$. This finding also provides support for the distinctiveness of the five constructs used.

Table 2 shows the scale means, standard deviations, reliabilities and correlations $(r)$. The main diagonal shows the alphas. The results in Table 2 do not support $H 5$ concerning the inter-correlation between the two studied categories of internet behaviour $(r=0.00$; $p$ n.s.). $H 2$ to $H 4$ were then tested using multiple hierarchical regressions (Cohen and Cohen, 1983), with the internet behaviours as the dependent variables (Table 2). We performed four steps. First, the control variables were entered in Step 1, followed by the justice construct and liking for the supervisor and satisfaction with supervisor performance in Step 2. The two-way interactions were added in Step 3. Finally, the calculations end with the addition of the three-way interaction in Step 4. The variables were centred in order to reduce multicollinearity (Aiken and West, 1991). Table 3 presents the results, including the standardised beta coefficients. Table 3 also shows $R^{2}$ at each step in the regressions, as well as the significance of the beta weights for the individual predictor variables in the final step. The statistical significance of the change in $R^{2}$ when the interaction terms were added was appraised to test the hypothesised moderating effects of liking for the supervisor and satisfaction with supervisor performance.

Table 3 Results of hierarchical regression analyses

\begin{tabular}{|c|c|c|c|c|}
\hline & \multicolumn{2}{|c|}{ Cyberloafing } & \multicolumn{2}{|c|}{ Cybercivism } \\
\hline & $\beta$ & $t$ & $\beta$ & $t$ \\
\hline \multicolumn{5}{|l|}{ Step 1} \\
\hline Gender & -0.233 & $-3.753 * * *$ & 0.108 & $1.683 \dagger$ \\
\hline Age & -0.152 & $-2.441 * *$ & 0.015 & 0.233 \\
\hline Doctorate & -0.088 & -1.425 & -0.048 & -0.755 \\
\hline$R^{2}$ & $0.076^{* * *}$ & & 0.014 n.s. & \\
\hline \multicolumn{5}{|l|}{ Step 2} \\
\hline $\mathrm{IJ}$ & 0.182 & 1.658 & -0.092 & -0.814 \\
\hline Liking for the supervisor & -0.118 & -1.164 & 0.169 & 1.624 \\
\hline Satisfaction with performance & -0.001 & -0.008 & 0.008 & 0.102 \\
\hline$\Delta R^{2}$ & 0.013 n.s. & & $0.013 \mathrm{n} . \mathrm{s}$ & \\
\hline \multicolumn{5}{|l|}{ Step 3} \\
\hline $\mathrm{IJ} \times$ liking for the supervisor & 0.164 & $2.353^{*}$ & -0.064 & -0.819 \\
\hline $\mathrm{IJ} \times$ satisfaction with performance & -0.239 & $-3.277 * * *$ & 0.157 & $2.066^{*}$ \\
\hline$\Delta R^{2}$ & $0.041^{* * *}$ & & $0.018 \dagger$ & \\
\hline \multicolumn{5}{|l|}{ Step 4} \\
\hline $\mathrm{IJ} \times$ liking $\times$ satisfaction with performance & -0.210 & $-2.204 *$ & -0.111 & -1.101 \\
\hline$\Delta R^{2}$ & $0.018^{*}$ & & 0.005 n.s. & \\
\hline Adjusted $R^{2}$ & 0.114 & & 0.014 & \\
\hline $\mathrm{F}(9,239)$ & $4.857^{* * *}$ & & 1.378 & \\
\hline
\end{tabular}

Notes: $N=270$. Levels of significance: $\uparrow p<0.1 ; * p<0.05 ;{ }^{* *} p<0.01$ and ${ }^{* * *} p<0.001$. 
Although the interaction effects are actually the main interest in this study, none of the independent variables showed a significant main effect on any of the internet behaviours. These results lead us to reject $H 1 \mathrm{a}$ and $1 \mathrm{~b}$. Next, two-way and three-way interactions were applied to test $H 2$ to $H 4$ (Steps 3 and 4; Table 3). Table 3 shows how the two-way interactions jointly explained a significant amount of incremental variance $\left(\Delta R^{2}=0.041\right.$; $p<0.001)$ in the case of cyberloafing, but almost negligible variance in cybercivism $\left(\Delta R^{2}=0.018 ; p<0.1\right)$. An inspection of the individual two-way interactions also revealed a significant moderating effect of satisfaction with supervisor performance on the relationship between IJ and cyberloafing $(B=-0.239 ; p<0.001)$ and cybercivism use $(B=0.157 ; p<0.05)$. This pattern supports $H 2 \mathrm{a}$ and $H 2 \mathrm{~b}$. An unexpected result occurred in the two-way interaction concerning employees with high, rather than low, liking for the supervisor. They actually displayed more cyberloafing $(B=0.164 ; p<0.05)$ and an insignificant amount of cybercivism $(B=-0.064 ; p$ n.s). These figures force us to reject $H 3 \mathrm{a}$ and $H 3 \mathrm{~b}$.

Finally, an examination of the three-way interactions (Step 4; Table 3) revealed that liking for the supervisor and satisfaction with supervisor performance jointly had a significant moderating effect on the IJ-cyberloafing link $(B=-0.210 ; p<0.05)$, but they failed to predict cybercivism $(B=-0.111 ; p$ n.s.). Thus, Step 4 also displays how the three-way interaction explains a significant amount of incremental variance in the case of cyberloafing $\left(\Delta R^{2}=0.018 ; p<0.05\right)$, but an insufficient amount in the case of cybercivism $\left(\Delta R^{2}=0.005 ; p\right.$ n.s. $)$. These results support $H 4 \mathrm{a}$, but not $H 4 \mathrm{~b}$. As Table 3 shows, the final adjusted $R$ square for cybercivism is 0.014 , thus suggesting that the model has very little explanation power for cybercivism. This forces us to drop the further analyses and discussion on the cybercivism results and focus only on cyberloafing.

The significant effects of the different interactions on internet behaviour involving satisfaction with supervisor performance, liking for the supervisor and IJ are represented graphically in Figure 2, following the method recommended by Aiken and West (1991). Figure 2 graphically presents the three-way interaction effects on cyberloafing. Only under combinations of liking for the supervisor and high levels of satisfaction with supervisor performance does IJ decrease cyberloafing. In contrast, IJ increases the level of cyberloafing activities under conditions of high liking for the supervisor and, in a spectacular fashion, when liking for the supervisor interacts with low satisfaction with supervisor performance.

\section{Discussion}

We can make several observations about the theoretical and practical implications of this study. Some refer to

- the nature of these behaviours, especially when compared to conventional OCB and deviance

- other implications seem to help to develop an intrinsically-oriented management strategy in a separate stream of the classic coercive control-punishment duo. 
The challenge of this work focuses on the figure of the supervisor as a fair authority figure. Beyond simply suggesting that perceptions of fair treatment may help to self-regulate internet behaviour, this study incorporates frequent feelings toward the figure of the supervisor and develops an intrinsically-oriented pattern that is practical and consistent with what happens during a normal work day.

- in addition to internet behaviour, this study also develops certain aspects of the literature on citizenship in general, especially focusing on the relationship between liking and appraisal of performance, which may also be contributing to internet behaviour.

First, contrary to expectations, there is no association between cyberloafing and cybercivism. They may not perform similarly to conventional deviance and citizenship, thus suggesting that employees may engage in both internet behaviours in a parallel way. Past research has pointed out the symmetry of conventional citizenship and deviance, by suggesting that these two behaviours are separate but correlated constructs (Kelloway et al., 1999). Apparently, consistent with the Fox and Spector (2006) discussion, the same employees who engage in conventional deviance could not concurrently engage in citizenship. This idea is not supported by our results with regard to the two studied categories of internet behaviour, since they appear to be two roles that can be performed by the same actor in a parallel manner. That is, employees could independently display negative (even ignoring constraints imposed by supervisors) and positive forms of internet behaviours as an unavoidable way to accomplish work or personal goals. This finding offers new insights into cyber behavioural reactions to IJ, by suggesting that the same managerial tools for eliciting cybercivism reactions may not be useful for discouraging cyberloafing, which could make the supervision of these behaviours more complicated. The distinct results of this study in predicting these two types of internet behaviour, using the same predictors, might be an indication of this.

The virtual component that is clearly present in the ontology of these two types of behaviours may influence these results. Neither does cyberloafing always seem to be a counter-productive reaction aimed at harming the organisation, nor does cybercivism always imply reciprocation for fair treatment by the supervisor. This assumption, usually framed within social exchange theory (Blau, 1964), suggests that an employee can use internet behaviours as a way of harming or rewarding (reciprocate for) his or her unjust organisation (or his/her supervisor, as an enactor of this in/justice). Elaborating on this quid pro quo rationale, in the case of cyber activity, the sources and foci of the employee reciprocation might be on both sides of the internet. As a result, although different employee feelings about the supervisor - liking, efficiency, and fairness (IJ) - would motivate different types of internet behaviours, they also have 'their own (virtual) WORLD'. When we focus on their virtual character, what are the motivations for internet behaviours? The answer to this question may involve studying 'the world of relationships' that each employee deploys over the internet.

Second, in any event, this study provides a new view of internet behaviour by developing specific managerial implications. By considering employee feelings about the supervisor, intrinsically-oriented self-regulatory strategies that focus on the role a fair authority figure can play in supervising internet behaviour may work better. As we suggested, surrounding and embedded in the relationship between IJ and employee behaviour, there are 
- emotions

- rationalisations.

Cybercivism appears to be behaviour that is not sensitive to employee emotions about the supervisor and is only triggered by IJ events when they interact with employee satisfaction with the supervisor's performance. However, as shown above, there are shortcomings in the explanation power of the cybercivism model that lead us to reject further discussion of its merits. The results on cyberloafing seem to be closer to our predictions. Cyberloafing seems to be influenced by both cognitive and affective mechanisms. This finding would extend prior research by Lim and Teo (2005), who only reported the involvement of rational neutralisations in the IJ-cyberloafing link. Although further examination of cyberloafing influences showed inconsistency, interacting with IJ, satisfaction with supervisor's performance was shown to decrease internet misuse, whereas, contrary to our expectations, liking for the supervisor actually increased it. These results confirm Mahatanankoon's (2006) predictions that social factors perform as moderating constraints that may limit or inhibit employees' responses to provocations with cyberloafing.

Meanwhile, support for the three-way interaction was encountered, showing the predicted negative effects on employees' cyberloafing. Figure 2 shows these results in detail. As we can see in Figure 2, the presence of high satisfaction with supervisor performance plays a key role in the ability of the three-way interaction to decrease internet misuse. Thus, high levels of satisfaction with supervisor performance, regardless of the different levels of liking for the supervisor, are always present when internet misuse decreases. Consistently, when low levels of satisfaction with supervisor performance are present, cyberloafing always increases through IJ and very significantly when employees score high (rather than low) on liking for the supervisor. This finding seems to support the virtues of supervisors managing cyberloafing by combining both fairness and high performance.

Figure 2 Three-way interaction effects of liking for the supervisor, satisfaction with supervisor's performance and IJ on cyberloafing

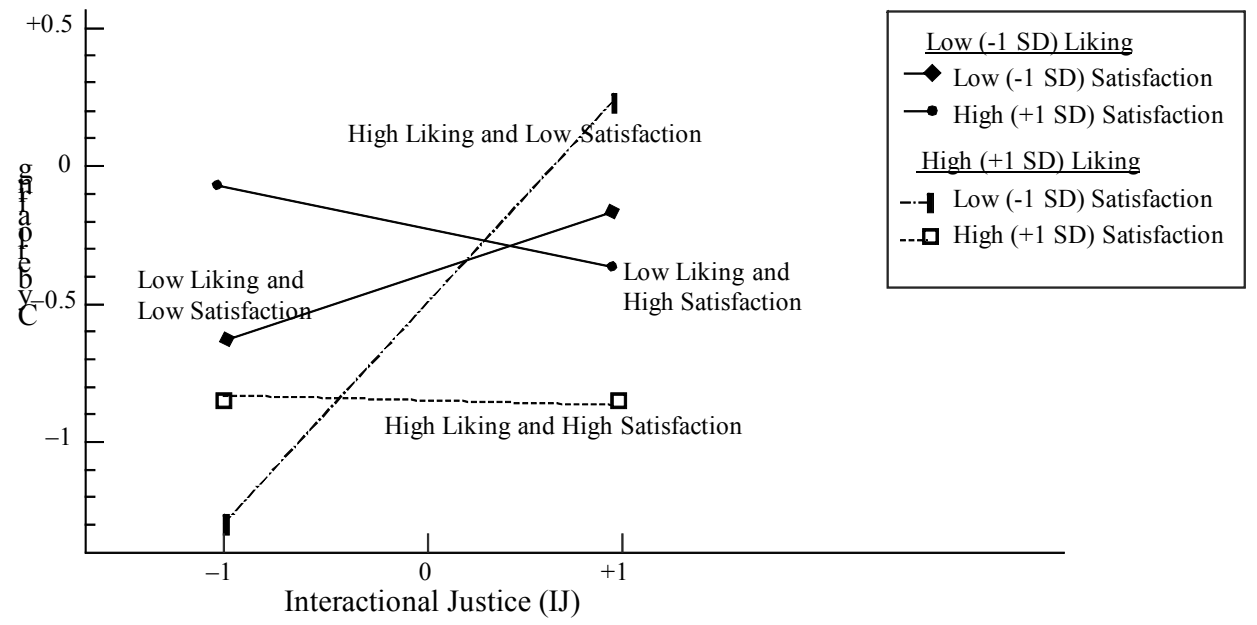


The results in Figure 2 also seem to question the ability of liking for the supervisor to decrease cyberloafing when performed through the three-way interaction. Certainly, internet misuse appears to be sensitive to liking for the supervisor, but the results clearly seem to reject the idea that this sensitivity may lead to beneficial influences and less cyberloafing. In fact, only when employees score both high on satisfaction with supervisor performance and low on liking for the supervisor is there a clear interacting influence that decreases cyberloafing (Figure 2). This result suggests that liking for the supervisor elicits the employee's perceptions that the supervisor has a good relationship with him or her and tolerates these behaviours, which means the employee may be more likely to engage in cyberloafing during the work day. As Garrett and Danziger (2008a) suggest, employees may use the internet for personal purposes at work for many of the same reasons that they use it elsewhere. The employee may even feel that the supervisor is confident that he or she is not doing anything that would harm the organisation. This reasoning may coincide with prior research pointing to employee beliefs that cyberloafing is not serious misconduct per se (e.g., Blanchard and Henle, 2008; Lim and Chen, 2012). It should also be pointed out that our sample is composed of higher-status employees (university instructors) who, contrary to conventional wisdom, engage in significantly more frequent cyberloafing (Garrett and Danziger, 2008b). In any event, liking for the supervisor alone does not appear to clearly follow the predicted patterns theoretically discussed; that is, liking for the supervisor is not able to translate either affective or cognitive states of unfairness into productive internet behaviour.

Finally, as we noted earlier, extensive research has focused on the relationship between liking and appraisal of performance (Bolino and Turnley, 2003; Ferris et al., 1994; Wayne and Ferris, 1990; Wayne and Liden, 1995) and addressed the citizenship behaviour consequences of this liking (Bolino et al., 2006). However, a focus on top-bottom hierarchical approaches (liking for and performance of subordinate) dominates these studies and so they disregard bottom-top approaches in predicting subordinate citizenship. Our findings lack support for moderating influences of subordinates' appraisals of managers and their liking for the supervisor on their cybercivism. Nevertheless, they represent an extension of the above-mentioned research in this area and on internet behaviour in general.

\section{Limitations and future research}

This study opens up several avenues for future research. First, there is a need for more research on the lack of sensitivity of cybercivism to the affective mechanisms and on 'the erratic employee engagement in cyberloafing'. Second, we consider that a complete approach to virtual citizenship and counterproductive behaviours remains unexplored in this paper. Given that ICTs appear capable of creating virtual behaviour, internet behaviour can not only be delivered online, but it can also comprise behaviour that does not come from the actions of a real person. In that case, future research could consider influences on internet behaviour that are not always the result of the action of a 'real supervisor'. Finally, since the virtual environment presents very serious social and psychological impediments to the accomplishment of virtual work, additional fundamental research about the role that internet behaviour plays within virtual groups seems necessary. 
Our study has strengths, but we also acknowledge that it has several weaknesses. First, it might suffer from mono-method/source bias. Second, the surveyed teachers have certain job conditions that are often inherent to their particular roles in universities and workers in the public sector. For instance, the teachers' immediate bosses probably have fewer opportunities to lead them than employers in the private sector do. Consequently, the performance of the constructs used in the present study, as well as their implications, could vary. Lastly, the data stem from a limited universe, raising concerns about the generalisability of the findings.

This paper, on the other hand, contributes to a better understanding of internet behaviour and its two-fold nature. By uncovering reasons that IJ ultimately triggers internet behaviour, it contributes to the success of intrinsically-oriented supervisory strategies by allowing fair authority figures to become more effective in managing internet behaviour. In addition, the suggestion that the two studied categories of internet behaviour may be not inter-correlated, and can hence be performed in a parallel manner, seems to open new avenues to successfully supervise these behaviours. The appropriateness of the supervisor profile should be a key issue when considering the management and promotion of desired internet behaviour, since both IJ and an alternative range of employees' healthy feelings about the supervisor seem necessary.

\section{References}

Aiken, L.S. and West, S.G. (1991) Multiple Regression: Testing and Interpreting Interactions, Sage, Newbury Park CA.

Aquino, K., Galperin, B.L. and Bennett, R. (2004) 'Social status and aggressiveness as moderators of the relationship between interactional justice and workplace deviance', Journal of Applied Psychology, Vol. 34, No. 5, pp.1001-1029.

Ball, G.A., Trevino, L.K. and Sims, H.P. (1994) 'Just and unjust punishment: influences on subordinate performance and citizenship', Academy of Management Journal, Vol. 37, No. 2, pp.299-322.

Bass, B. (1990) Bass and Stogdill's Handbook of Leadership: Theory, Research, and Managerial Applications, Free Press, New York, NY.

Bernardin, H.J. (1986) 'Subordinate appraisal: a valuable source of information about managers', Human Resource Management, Vol. 25, No. 3, pp.421-439.

Beugré, C.D. (2006) 'Understanding dysfunctional cyberbehavior: the role of organizational justice', in Anandarajan, M., Teo, T. and Simmers, C. (Eds.): The Internet and Workplace Transformation, M.E. Sharpe, Armonk, NY, pp.223-239.

Bies, R.J. and Moag, J.S. (1986) 'Interactional justice: communication criteria of fairness', Research on Negotiation in Organizations, Vol. 1, pp.43-55.

Blanchard, A.L. and Henle, C.A. (2008) 'Correlates of different forms of cyberloafing: the role of norms and external locus of control', Computers in Human Behavior, Vol. 24, pp.1067-1084.

Blau, P.M. (1964) Exchange and Power in Social Life, New York, John Wiley and Sons.

Bock, G-W. and Ho, S.L. (2009) 'Non-work related computing (NWRC)', Communications of the $A C M$, Vol. 52, No. 4, pp.124-128.

Bolino, M.C. and Turnley, W.H. (2003) 'Counternormative impression management, likeability, and performance ratings: the use of intimidation in an organizational setting', Journal of Organizational Behavior, Vol. 24, pp.237-250.

Bolino, M.C., Varela, J.A., Bande, B. and Turnley, W.H. (2006) 'The impact of impressionmanagement tactics on supervisor ratings of organizational citizenship behavior', Journal of Organizational Behavior, Vol. 27, pp.281-297. 
Borman, W.C. and Motowidlo, S.J. (1997) 'Task performance and contextual performance: the meaning for personnel selection research', Human Performance, Vol. 10, No. 2, pp.99-109.

Cohen, J. and Cohen, P. (1983) Applied Multiple Regression/Correlation Analysis for the Behavioral Sciences, 2nd ed., Hillsdale, Erlbaum, NJ.

Ferguson, S.D. and Ferguson, S. (1988) Organizational Communication, 2nd ed., New Brunswick, Transaction Publishers (Rutgers University), NJ.

Ferris, G.R., Judge, T.A., Rowland, K.M. and Fitzgibbons, D.E. (1994) 'Subordinate influence and the performance evaluation process: test of a model', Organizational Behavior and Human Decision Processes, Vol. 58, pp.101-135.

Folger, R. and Skarlicki, D.P. (1998) 'A popcorn metaphor for workplace violence', in Griffin, R.W., O'Leary-Kelly, A. and Collins, J. (Eds.): Dysfunctional Behavior in Organizations: Violent and Deviant Behavior, (JAI Press, Stamford, CT), Vol. 23, pp.43-81.

Fox, A. (2007) 'Caught in the web, HR Magazine', Society for Human Resource, Vol. 52, pp.35-39.

Fox, S. and Spector, P.E. (2006) 'Deviant and citizen: same actor two roles?', Paper presented at Academy of Management Professional Meeting, 11-16 August, Atlanta, Georgia, USA.

Garrett, R.K. and Danziger, J.N. (2008a) 'Disaffection or expected outcomes: understanding personal internet use during work', Journal of Computer Mediated Communication, Vol. 13, No. 4, pp.937-958.

Garrett, R.K. and Danziger, J.N. (2008b) 'On cyberslacking: workplace status and personal internet use at work', CyberPsychology \& Behavior, Vol. 11, No. 3, pp.287-292.

Greenberg, J. (1993) 'Stealing in the name of justice: informational and interpersonal moderators of theft reactions to underpayment inequity', Organizational Behavior and Human Decision Processes, Vol. 54, pp.81-103.

Henle, C.A. and Blanchard, A.L. (2008) 'The Interaction of work stressors and organizational sanctions on cyberloafing', Journal of Managerial Issues, Vol. 20, No. 3, pp.383-400.

Henle, C.A., Kohut, G. and Booth, R. (2009) 'Designing electronic use policies to enhance employee perceptions of fairness and to reduce cyberloafing: an empirical test of justice theory', Computers in Human Behavior, Vol. 25, No. 4, pp.902-910.

Hovorka-Mead, A.D., Ross, W.H., Whipple, T. and Renchin, M.B. (2002) 'Watching the detectives: seasonal student employee reactions to electronic monitoring with and without advance notification', Personnel Psychology, Vol. 55, No. 2, pp.329-362.

IJsselsteijn, W., van Baren, J. and van Lanen, F. (2003) 'Staying in touch: social presence and connectedness through synchronous and asynchronous communication media', in Stephanidis, C. and Jacko, J. (Eds.): Human-Computer Interaction: Theory and Practice (Part II), Volume 2 of the Proceedings of HCI International 2003, Lawrence Erlbaum, Hillsdale, NJ, pp.924-928.

Judge, T.A., Scott, B.A. and Ilies, R. (2006) 'Hostility, job attitudes, and workplace deviance: test of a multilevel model', Journal of Applied Psychology, Vol. 91, pp.126-138.

Kelloway, K., Loughlin, C., Barling, J. and Nault, A. (1999) 'Counterproductive and organizational citizenship behaviours; separate but related constructs', International Journal of Selection and Assessment, Vol. 10, pp.143-151.

Lea, M. and Spears, R. (1992) 'Paralanguage and social perception in computer-mediated communication', Journal of Organizational Computing, Vol. 2, No. 3, pp.321-341.

Lee, K. and Allen, N.J. (2002) 'Organizational citizenship behavior and workplace deviance: the role of affect and cognitions', Journal of Applied Psychology, Vol. 87, pp.131-142.

Lee, S.M., Lee, S.G. and Yoo, S. (2004) 'An integrative model of computer abuse based on social control and general deterrence theories', Information \& Management, Vol. 41 No. 6, pp.707-718.

Liao, Q., Luo, X., Gurung, A. and Li, L. (2010) 'Workplace management and employee misuse: does punishment matter?', Journal of Computer Information Systems, Vol. 50 No. 2, pp.49-59. 
Lim, V.K.G. (2002) 'The IT way of loafing on the job: cyberloafing, neutralizing and organizational justice', Journal of Organizational Behavior, Vol. 23, pp.675-694.

Lim, V.K.G. and Chen, D.J.Q. (2012) 'Cyberloafing at the workplace: gain or drain on work?' Behaviour and Information Technology, first published on 11 November 2009 (iFirst), Vol. 31, No. 4.

Lim, V.K.G. and Teo, T.S.H. (2005) 'Cyberloafi ng and organizational justice', in Anandarajan, M., Teo, T. and Simmers, C. (Eds.): The Internet and Workplace Transformation, pp.241-258, M.E. Sharpe, Armonk, NY.

Lord, R.G., Brown, D.J., Harvey, J.L. and Hall, R.J. (2001) 'Contextual constraints on prototype generation and their multilevel consequences for leadership perceptions', Leadership Quarterly, Vol. 12, pp.311-338.

Mahatanankoon, P. (2006) 'Internet abuse in the workplace: extension of workplace deviance model', in Anandarajan, M., Teo, T. and Simmers, C. (Eds.): The Internet and Workplace Transformation, pp.15-27, M.E. Sharpe, Armonk, NY.

Malachowski, D. (2005) Wasted Time at Work Costing Companies Billions, in Business, available at SFGate website http://www.sfgate.com/bin/.cgi?f=///2005///.TMP (accessed on 30 October 2006).

Maruping, L.M. and Agarwal, R. (2004) 'Managing team interpersonal processes through technology: a task-technology fit perspective', Journal of Applied Psychology, Vol. 89, No. 6, pp.975-990.

Moorman, R.H. (1991) 'The relationship between organizational justice and organizational citizenship behavior: do fairness perceptions influence employee citizenship?', Journal of Applied Psychology, Vol. 76, pp.845-855.

Nunnally, J.C. (1978) Psychometric Theory, 2nd ed., McGraw-Hill, New York.

Organ, D.W. (1988) Organizational Citizenship Behavior: The Good Soldier Syndrome, Lexington Books, Lexington, MA.

Organ, D.W. (1997) 'Organizational citizenship behavior: it's construct cleanup time', Human Performance, Vol. 10, No. 2, pp.85-97.

Organ, D.W., Podsakoff, P.M. and MacKenzie, S.B. (2006) Organizational Citizenship Behavior: Its Nature, Antecedents, and Consequences, Sage, Thousand Oaks, CA.

Skarlicki, D.P. and Latham, G.P. (1997) 'Leadership training in organizational justice to increase citizenship behavior within a labor union: a replication', Personnel Psychology, Vol. 50, pp.617-634.

Spector, P.E. and Fox, S. (2002) 'An emotion-centered model of voluntary work behavior: some parallels between counterproductive work behavior (CWB) and organizational citizenship behavior (OCB)', Human Resource Management Review, Vol. 12, pp.269-292.

Stanton, J.M. (2000) 'Traditional and electronic monitoring from an organizational justice perspective', Journal of Business and Psychology, Vol. 15, No. 1, pp.129-147.

Van Dyne, L., Cummings, L.L. and Parks, J.M. (1995) 'Extra-role behaviors: in pursuit of construct and definitional clarity (a bridge over muddied waters)', in Cummings, L.L. and Staw, B.M. (Eds.): Research in Organizational Behavior, Vol. 17, pp.215-285, JAI, Greenwich, CT.

Walther, J.B. (1992) 'Interpersonal effects in computer mediated interaction: a relational perspective', Communication Research, Vol. 19, No. 1, pp.52-90.

Wayne, S.J. and Ferris, G.R. (1990) Influence tactics, affect, and exchange quality in supervisor-subordinate interactions: a laboratory experiment and field study, Journal of Applied Psychology, Vol. 75, pp.487-499.

Wayne, S.J. and Liden, R.C. (1995) 'Effects of impression management on performance ratings: a longitudinal study', Academy of Management Journal, Vol. 38, pp.232-260.

Weiss, H.M. and Cropanzano, R. (1996) 'Affective events theory: a theoretical discussion of the structure, causes, and consequences of affective experiences at work', Research in Organizational Behavior, Vol. 18, pp.1-74. 
Williams, L.J. and Anderson, S.E. (1991) 'Job satisfaction and organizational commitment as predictors of organizational citizenship and in-role behaviors', Journal of Management, Vol. 17, No. 3, pp.601-617.

Yen, J.R., Li, E.Y. and Niehoff, B.P. (2008) 'Do organizational citizenship behaviors lead to information system success? Testing the mediation effects of integration climate and project management', Information \& Management, Vol. 45, No. 6, pp.394-402.

Zoghbi-Manrique-de-Lara, P. (2007) 'Redefining OCB as cybercivism: do work attitudes also explain organizational citizenship internet behaviors?', Management Research, Vol. 5, No. 1, pp.43-52.

Zoghbi-Manrique-de-Lara, P. (2011) Reconsidering the Boundaries of the Cyberloafing Activity: The Case of a University, Behaviour \& Information Technology, first published on 24 January 2011 (iFirst).

Zoghbi-Manrique-de-Lara, P. and Melián-González, S. (2009) 'The role of anomia on the relationship between organisational justice perceptions and organisational citizenship online behaviours', Journal of Information, Communication and Ethics in Society, Vol. 7, No. 1, pp.72-85.

Zoghbi-Manrique-de-Lara, P., Tacoronte, D.V. and Ding, J.M.T. (2006) 'Do current anti-cyberloafing disciplinary practices have a replica in research findings?: A study of the effects of coercive strategies on workplace internet misuse', Internet Research, Vol. 16, No. 4, pp.450-467.

\section{Appendix}

\section{Results of the CFA}

\begin{tabular}{lc}
\hline All variables items & $\begin{array}{c}\text { Factor } \\
\text { loadings }\end{array}$ \\
\hline IJ & \\
My supervisor... & 0.92 \\
Takes steps to deal with me in a truthful manner & 0.91 \\
Considers my viewpoint & 0.88 \\
Provides me with timely feedback about decisions and their implications & 0.87 \\
Is able to suppress personal bias & 0.86 \\
Treats me with kindness and consideration & 0.77 \\
Shows concern for my rights as an employee & \\
Employee's liking of the supervisor & 0.93 \\
I really like my supervisor as a person & 0.89 \\
I think my supervisor would make a good friend a good friend & 0.90 \\
I have a good relationship with my supervisor & \\
Employee's satisfaction with the supervisor's performance & 0.77 \\
My supervisor generally looks out for his/her own interests $(R)$ & 0.59 \\
My supervisor generally sets a good example in fulfilling his or her obligations & 0.82 \\
My supervisor generally seems capable and efficient & 0.64 \\
I have a poor opinion of my supervisor $(R)$ &
\end{tabular}

Notes: $(R)$ : reverse scored items; GFI: goodness fit index; CFI: comparative fit index; NFI: normed fit index; RMSEA: root mean square error of approximation; df: degrees of freedom. 
Whether satisfaction with and liking for the supervisor

Results of the CFA (continued)

\begin{tabular}{lc}
\hline All variables items & $\begin{array}{c}\text { Factor } \\
\text { loadings }\end{array}$ \\
\hline Cyberloafing & \\
I use internet at work to & 0.79 \\
Visit websites and digital newspapers to seek personal information & 0.78 \\
Download software or files for personal or family use & 0.74 \\
Read or send personal (non-work) e-mails & 0.75 \\
Visit the website of my bank to look at my account & 0.66 \\
Surf the net and thereby escape a little & \\
Cybercivism & 0.45 \\
When I am connected to the internet & 0.87 \\
I reply to misdirected e-mails if I can help the senders & 0.58 \\
I make suggestions about my university website problems in order to improve it & \\
I take care that my university net avoids virus risks and other threats & \\
Cmin $=330.314$, df $=179, \mathrm{p}<0.0001$, Cmin/df $=1.845$ & \\
GFI $=0.900$, CFI $=0.961$, NFI $=0.919$, RMSEA $=0.056$ &
\end{tabular}

Notes: $(R)$ : reverse scored items; GFI: goodness fit index; CFI: comparative fit index; NFI: normed fit index; RMSEA: root mean square error of approximation; df: degrees of freedom. 